\title{
GAIA Level 2a Fetal Growth Restriction
}

National Cancer Institute

\section{Source}

National Cancer Institute. GAIA Level 2a Fetal Growth Restriction. NCI Thesaurus. Code C128723.

GAIA Level 2a Fetal Growth Restriction is defined by two criteria: first, Level 2 evidence of pregnancy dating; second, at least one of the following requirements must be met: a) Estimated fetal weight below the third percentile using locally-accepted growth curve; OR b) Estimated fetal weight below the tenth percentile using locally-accepted growth curve AND either findings of absent or reversed end-diastolic flow of the umbilical artery Doppler OR a finding of oligohydramnios. 